\title{
A Summary Report on the Senior Administrative Personnel Overseas-Study Team of Yunnan Provincial Higher Education in 2016
}

\author{
Yongkun Wan \\ Yuxi Teachers College, Yuxi Municipality in Yunnan Province of China \\ wanyongkun123@163.com
}

Keywords: Senior administrative personnel; Overseas-study team; Langara college of Canada ; BC province's higher education; Yunnan provincial higher education

\begin{abstract}
From September 18 to December 18 in 2016, the 20-people Senior Executives Study-abroad Team of Yunnan Provincial Higher Education went to Langara College in Vancouver of Canada for three months of study. Through careful study and understanding of all the learners of this team towards Canadian fundamental realities, its multiple culture, BC Province's higher education concept, mechanism, policy and operation, every trainee's cognition about Canada and western countries' higher education characteristics and operational ways of western colleges and universities has been promoted. Furthermore, every trainee has been stimulated to positively think about how to promote the higher education in Yunnan province and improve the talent-cultivation quality. It is every trainee's common feeling that the study broadened their vision, enriched their concept and knowledge, built up their confidence, and made them learn more useful things, which would play a positive role in improving their work and their schools' work.
\end{abstract}

\section{Learning Organization Affairs}

The study team consists of administrative cadres from 13 colleges under the guidance of Foreign Cooperation and Communication Department of Yunnan Education Bureau. The study period lasted from 18 September to 18 December 2016, which was 3 months. During this period, the major study contents involved 14 subjects including Canada and BC Province's higher education management mechanism, BC Province's credit transfer system, college strategic plans, college leadership strategies, etc. The study contents also included 7 outside-college visits, 5 culture \& art gallery visits and 1 aboriginal community visit. This study took class lecture, guest speech and field visits as its major forms.

These studies made all team members have a deep understanding towards Canada and BC Province development history, social cultural characteristics and educational systems and made the members feel and experience Canadian local customs and practices, social economy and culture development, Canadian citizens' high quality and advanced social management concepts. In the meanwhile, everyone began to understand and think about similarities, differences and corresponding reasons among higher education management systems, teaching concepts and managerial ways between China and Canada as well as Yunnan Province and BC Province.

\section{Basic Facts of Higher Education in BC Province of Canada[1]}

BC Province has more than 60 colleges and universities, among which 25 are public ones. There were more than 400, 000 students (including students of various levels) in the year 2015/2016 with standard number of 181, 100 students (FTEs, equivalent to the number of students of full-time education) who enjoyed government funding.

BC Province belongs to one of the developed areas for Canadian higher education (called as post-secondary education), where public colleges and universities play the main role. Private schools have huge gaps compared with those public ones in terms of influence, number of students and education quality. BC Province higher education consists of university, university college, 
community college and technical college. In practice, universities enjoy high degrees of autonomous running with focus on bringing up research talents and degree-related courses while focusing on teaching research and innovation, which are cradles for doctors, masters and bachelors. BC Province now has 7 universities. Community colleges and technical colleges have to accept more management from government with focus on bringing-up special technical talents for employment market. The courses are mainly practical 2-to-3-year diploma courses, certificate courses and credit or degree transfer courses with a few pragmatic bachelor degree courses. University colleges' autonomous rights and available courses are somewhere between those two mentioned above. There are 3 university colleges in BC now.

\section{Inspiration and Consideration for Yunnan Provincial Higher Education}

\section{Credit Transfer System Could Be a Beneficial Attempt for Yunnan Higher Education Reform[2, 3]}

First, credit system could be implemented phase-by-phase and step-by-step. We cannot require the whole country adopt unified credit transfer system due to unbalanced development of social economy and education, however, mutual acknowledgement of similar courses' credits within inter-regions and inter-universities scope could be realized through signing credit mutual acknowledgement agreement on the base of comparing course goals and contents.

Second, we could adopt multiple modes. With the experience of BC Province, we could adopt credit transfer among courses, among majors, among universities and among different majors. We could also set up "lifetime credit bank" and study achievement authentication system.

Third, we should set up integrated credit transfer system with reasonable management mechanism, charging mechanism and complete higher education administration of students' enrollment status, providing students with opportunities of self-choosing majors or universities to maintain and improve students' study motivation.

Fourth, we should complete the construction of organizations and structures to from such two layers as credit transfer and information management. Credit transfer standards of systematic credit frame should be constructed and construction of online teaching and credit information system should be enhanced, which are foundation work for promoting credit transfer system.

Fifth, higher education course assessment committee for credit mutual acknowledgement should be set up and the format of talent cultivation plans should be unified where the courses for freshman and sophomore students should be general courses and foundational major courses to carry out dynamic management of "survival of the fittest". Expanding course contents, increasing minor courses and providing channels for accumulating credits are also foundation work for promoting credit transfer system.

Sixth, quality education and higher education reform should be promoted. With the development of our country's social economy and higher demands of people towards education and its quality, the existing education management system could no longer suit for the aim of free and all-around growth of human. The concept and practice of credit transfer system provide us with the references and answers to how to reform and how to find out the proper ways for reform, which could be a break-through for Yunnan provincial comprehensive deepened reform for the education field. The biggest beneficiaries are students, the indirect beneficiaries are the families and the society, and the ultimate beneficiaries should be our nation and country.

\section{Construction of Student-oriented Service Management System[4, 5]}

First, the administration of colleges and universities should be by law to build up a set of scientific, standardized and integrated system for student affairs. Responsibilities, rights and benefits should be clearly separated among higher education schools, social functional departments, working units or personnel that undertake logistic work, students and families.

Second, concepts should be changed to build up "student-oriented" concept for education and 
administration, and "administration" should be turned into "guidance". The change from single mode of education and administration to the comprehensive mode of education, administration, guidance and service should be finished as soon as possible for student affairs.

Third, the construction of work team for student affairs should be enhanced to put more energy on professionalization and specialization of management for student affairs.

Fourth, the mode of student management should be changed into open style to bring students' main functions into full play. The scope and depth of students participating management should be expanded, and the scientific and democratic level of school management work should be improved.

Fifth, the guidance of mainstream ideology should be persisted and more energy should be put on political education for whole personnel and its effectiveness.

Promoting the Close Cooperative Relationships among Colleges and Universities and Relationships among Universities and Enterprises[6, 7]

First, it is an important basis for benefit-related parties carrying out sound cooperation to build up the concepts of contract. Canadian colleges and universities emphasize cooperation, which has been widely acknowledged in the world especially in terms of its cooperative education.

Second, it is necessary to innovate concepts and mechanisms for improving cooperative education level in Yunnan higher education schools. The integrated educational thinking of production-study-research and the mode of "order-oriented training" go in accordance with the guidance and origins of Canadian cooperative education, which are all resource integration fundamentally to improve talent cultivation quality.

Third, the cooperative experience among Canadian colleges and universities could be used as reference for the development of Yunnan higher education. Yunnan is an underdeveloped province which relatively lacks educational resources especially high quality educational resources. BC's credit transfer system play an important role in integrating higher education school resources, which we could refer to and do some reform exploration with our realities.

\section{Improving the Scientificalness and Effectiveness of Financial Budget Management [8, 9]}

The first is to enforce the investment in higher education. On one hand, government should ensure the normal increase of fund-allocation limit for per capita student, on the other hand, government should relax the limit over student-recruiting norms to enable higher education schools to increase the number of recruiting students gradually.

The second is to endow colleges and universities with autonomous rights of running schools and respect regular patterns and features thereof. Government should allocate colleges and universities the funds in a lump sum according to types of colleges and universities and student cultivation costs, and the funds shall be under unified use of colleges and universities. And government should not take colleges and universities into the management of zero-balance accounts anymore, permitting colleges and universities to self-organize equipment bidding procurement.

The third is to refer to and learn from the advanced experience of Canadian budget among colleges and universities, improving the time, methods and scientificalness in making colleges and universities budget.

Seizing the Development Opportunity of Education Internationalization[10, 11]

Governments at all levels and colleges \& universities in Yunnan Province should give deep consideration to how to realize the Yunnan development positioning of "the Radiation Center Facing South Asia and South East Asia" with the state grand background of "One Belt and One Road" strategy. And Yunnan higher education should explore with great bravery and sense of responsibility in the construction process of the center to play important roles and stick to the "Walking outside and Inviting inside" principle, constantly improving the internationalization level of Yunnan featured higher education.

The first is to enhance the construction of software and hardware in higher education schools, to set improving talent cultivation quality as goals, to improve education teaching methods, to create fine study environment, to enhance the construction of bilingual teaching, to improve management 
technique measures, to enhance construction of service facilities, to increase the ratio of high-end consumption, and to provide necessary material conditions for recruiting international students.

The second is to enhance the effort of selecting teachers and students in colleges \& universities for overseas communication, research and training, to increase their overseas-study experience, to absorb advanced technological and managerial experience, to promote the quick all-around self-development, and to enforce the international competitive power of Yunnan colleges \& universities.

The third is to explore development space for Yunnan Provincial higher education, to output diploma education abroad through cooperative programs, to specially make use of geographical advantage, to cooperate with various colleges and universities in developing countries and to recruit local students and award them Chinese diplomas.

The fourth is to introduce foreign advanced teaching resources. To introduce them within universities' majors courses which are of general international laws and regulations, economic globalization achievements and questions as well as multiple culture communications, to cultivate talents with worldview and world economic \& cultural communication abilities, and to lay cultural foundation for them stepping into the world, integrating with the world and serving the world in a better way.

The fifth is to cultivate students' market thinking and international view, and to provide abundant human resource and intelligence assurance for turning Yunnan into the radiation center facing South Asia and Southeast Asia.

\section{Acknowledgements}

Finally, we want to express our heartiest thanks to Yunnan Education Bureau for providing us with this precious study chance, to Langara College for each learning it arranges, and to supports from our colleges. We shall apply what we have learned and thought about to future work, making due contributions to the constant development of Yunnan education cause.

\section{References}

[1] https://www2.gov.bc.ca/gov/content/education-training/post-secondary-education

[2] L. Kong and S.X. Yin: Comparative Study on Credit Accumulation and Transfer System in Europe and North America: Case Study of European Credit Transfer System and Canadian British Colombia Credit Transfer System, Journal of Distance Education. Vol.03(2012)No.3, p.44-51.

[3] S.T. Zhao and M. Xu: Analysis on Credit Accumulation and Transfer System of Higher Education in Canada, Studies in Foreign Education. Vol.42(2016)No.12, p.67-78.

[4] X.J. Zhang: Canadian Student Service and Its Enlightenment to Chinese Universities, Beijing Education. Vol.11(2011)No.11, p.75-77.

[5] J. Liu: Investigation of Students Management at Canada's Community Colleges and Its Inspiration to China, Journal of Tianjin Institute of Financial and Commercial Management. Vol.14(2012)No.4, p.62-64.

[6] L.P. Chai: Research on Cooperative Education of Canadian Universities(M.S., Tianjin Normal University, China 2012), p.34-37.

[7] M.M. Yu: Enlightenment of Canadian Cooperative Education to Chinese Universities, Chinese University Science and Technology. Vol.01(2014)No.Z1, p.57-59.

[8] Z.Y. Wang and S.M. Li: On funds shortage of Local Normal Universities in China from Canadian Strategies for Its Higher Education Funding, Journal of Tianjin Academy of Educational Science. Vol.01(2009)No.1, p.76-77. 
[9] C.Y. Mao: Characteristics and References of Financial Management and Internal Audit in Canadian Universities, Journal of Nanjing Institute of Industry Technology. Vol.12(2012)No.4, p.77-80.

[10] Q.Y. Cheng and Yong Shi: On the Problems in the Process of Internationalization in Yunnan Higher Education, Journal of Yunnan RTV University. Vol.14(2012)No.3, p.56-59.

[11] Y.L. Wu and S.B. Li: Analysis on New Strategies of Internationalization of Canadian Higher Education, Journal of World education. Vol.16(2012)No.16, p.60-65. 